Kansas State University Libraries

New Prairie Press

\title{
BIOAVAILABILITY AND CV COMPONENT COMPARISON IN A CROSSOVER
}

Zhiming Wang

Vince A. Uthoff

Follow this and additional works at: https://newprairiepress.org/agstatconference

Part of the Agriculture Commons, and the Applied Statistics Commons

\section{(c) $($ () $\ominus$}

This work is licensed under a Creative Commons Attribution-Noncommercial-No Derivative Works 4.0 License.

\section{Recommended Citation}

Wang, Zhiming and Uthoff, Vince A. (1997). "BIOAVAILABILITY AND CV COMPONENT COMPARISON IN A CROSSOVER," Conference on Applied Statistics in Agriculture. https://doi.org/10.4148/2475-7772.1302

This is brought to you for free and open access by the Conferences at New Prairie Press. It has been accepted for inclusion in Conference on Applied Statistics in Agriculture by an authorized administrator of New Prairie Press. For more information, please contact cads@k-state.edu. 


\title{
BIOAVAILABILITY AND CV COMPONENT COMPARISON IN A CROSSOVER
}

\author{
Zhiming Wang, Vince A. Uthoff \\ Quintiles/Innovex \\ 11250 Corporate Ave \\ Lenexa, KS 66219
}

\begin{abstract}
Two medication formulations are compared using noncompartmental pharmacokinetic (PK) variables. However, more than the ratio of mean effects is of interest. A difference in formulation coeficients of varication (CV), within- or between-subject, is sought. The experimental design chosen is a 2 sequence crossover design of the form $\mathrm{ABBA}$ and $\mathrm{BAAB}$, where $\mathrm{A}$ and $\mathrm{B}$ are two medication formulations. A mixed linear model is defined that contains random effects for subjects and for subject by formulation interactions. The model has fixed effects for the average formulation effects and period effects. The 2 formulations are assumed to have different error terms. The average formulation effect ratios and within-subject CVs may be compared by usual methods. An approximate Z-statistic is computed to compare the betweensubject CVs. This statistic assumes a correlation of the 2 between-subject CV estimates. In addition, a tractable variance ratio is defined to indicate the extent to which the average effects ratio is applicable to each subject.
\end{abstract}

Keywords: bioavailability, bioequivalence, variance component, pharmacokinetics 


\section{Introduction}

In testing for bioequivalence, the focus is usually on showing that the average areas under the blood level curve (AUC) of two formulations differ by no more than $20 \%$. Little attention is given to the variability of the AUC. Usually variances are assumed to be equal. It is also standard practice to use a crossover design because crossover designs require fewer subjects and carryover effects have not been a major problem in bioequivalence studies.

If, however, the original formulation has shown a large within- and between-subject variability, it might be of interest to see if the new formulation might not produce a smaller variation. Thus, the estimation and testing of variances can be of as much interest as can be the mean effects.

A second assumption usually made is that the average bioequivalence is applicable to each and every patient who takes the drug. That is, it is assumed that the test formulation cannot be $>20 \%$ more bioavailable in one patient while the standard formulation is $>20 \%$ more bioavailable in a second patient.

We have data from a 4-period, 2-sequence crossover design of the form ABBA and BAAB, where $\mathrm{A}$ and $\mathrm{B}$ are two medication formulations. We are interested in estimating and testing the between-subject variance component, the within-subject variance component, the average bioavailability and to provide some kind of assessment of the extent to which the average bioavailability is applicable to each and every patient. This was also a compound for which the standard formulation had shown both a large within- and between-subject variance components in previous pharmacokinetic studies.

Most of what was requested was fairly straight forward. However, the testing of the betweensubject variance component presented a challenge. Most linear models for this kind of a design assume a constant between-subject variance component called, "the subject effect." Since the design is a crossover, any two estimates of the between-subject variance components are correlated. In most tests for variance components, the components are assumed to be independent and this cannot hold if 2 different between-subject variance components are estimated from the same subjects.

A second challenge was posed by determining how to best define an index of the degree to which the average bioavailability is applicable to each patient. 


\section{Variance Component Analysis of PK Parameters}

Let treatment A be a capsule and treatment B be a tablet. Each subject received 2 treatments in 4 different periods depending on his assigned treatment sequence. A subject assigned to sequence 1 received A, B, B, A at period 1, 2, 3, 4, respectively. A sequence 2 subject received $\mathrm{B}, \mathrm{A}, \mathrm{A}$, B.

Let

$\mathrm{S} \sim \mathrm{N}\left(0, \sigma_{\mathrm{S}}{ }^{2}\right)$ be the subject effect, $\mathrm{T}_{\mathrm{SA}} \sim \mathrm{N}\left(0, \sigma_{\mathrm{A}}{ }^{2}\right)$ be the treatment $\mathrm{A}$ by subject interaction, $\mathrm{T}_{\mathrm{SB}} \sim \mathrm{N}\left(0, \sigma_{\mathrm{B}}{ }^{2}\right)$ be the treatment $\mathrm{B}$ by subject interaction, $\epsilon_{\mathrm{Si}} \sim \mathrm{N}\left(0, \sigma_{\epsilon}{ }^{2}\right)$ be the within-subject error for treatment $A$, $\eta_{\mathrm{Si}} \sim \mathrm{N}\left(0, \sigma_{\eta}{ }^{2}\right)$ be the within-subject error for treatment B.

Then, for a subject in sequence ABBA, the linear models for the observation on each subject at each period can be written as follows:

period1: $\quad \mathrm{y}_{\mathrm{S} 11}=\mu+\mathrm{S}+\mathrm{T}_{\mathrm{SA}}+\tau_{\mathrm{A}}+\pi_{1}+\epsilon_{\mathrm{S} 1}$,

period2: $\quad \mathrm{y}_{\mathrm{S} 12}=\mu+\mathrm{S}+\mathrm{T}_{\mathrm{SB}}+\tau_{\mathrm{B}}+\pi_{2}+\eta_{\mathrm{S} 1}$,

period3: $\quad \mathrm{y}_{\mathrm{S} 13}=\mu+\mathrm{S}+\mathrm{T}_{\mathrm{SB}}+\tau_{\mathrm{B}}+\pi_{3}+\eta_{\mathrm{S} 2}$,

period4: $\quad \mathrm{y}_{\mathrm{S} 14}=\mu+\mathrm{S}+\mathrm{T}_{\mathrm{SA}}+\tau_{\mathrm{A}}+\pi_{4}+\epsilon_{\mathrm{S} 2}$.

Similarly for a subject in sequence BAAB, the linear models can be written as follows for each period.

period1: $\quad \mathrm{y}_{\mathrm{S} 21}=\mu+\mathrm{S}+\mathrm{T}_{\mathrm{SB}}+\tau_{\mathrm{B}}+\pi_{1}+\eta_{\mathrm{S} 1}$,

period2: $\quad \mathrm{y}_{\mathrm{S} 22}=\mu+\mathrm{S}+\mathrm{T}_{\mathrm{SA}}+\tau_{\mathrm{A}}+\pi_{2}+\epsilon_{\mathrm{S} 1}$,

period3: $\quad y_{S 23}=\mu+S+T_{S A}+\tau_{A}+\pi_{3}+\epsilon_{S 2}$,

period4: $\quad \mathrm{y}_{\mathrm{S} 24}=\mu+\mathrm{S}+\mathrm{T}_{\mathrm{SB}}+\tau_{\mathrm{B}}+\pi_{4}+\eta_{\mathrm{S} 2}$.

In the models above, $\mu, \tau_{A}, \tau_{B}, \pi_{1}, \pi_{2}, \pi_{3}$, and $\pi_{4}$ are fixed effects. These denote the intercept, fixed treatment effects and fixed period effects. It is assumed that $\mathrm{N}_{1}$ subjects are assigned to sequence 1 and $N_{2}$ subjects are assigned to sequence 2 and $N=N_{1}+N_{2}$.

Note that the fixed period effects could be made sequence dependent without changing the results which follow.

For sequence ABBA, let

$$
\begin{aligned}
& \mathrm{Z}_{\mathrm{S} 1}=\left(\mathrm{y}_{\mathrm{S} 11}+\mathrm{y}_{\mathrm{S} 14}\right) / 2=\mu+\mathrm{S}+\mathrm{T}_{\mathrm{SA}}+\tau_{\mathrm{A}}+\left(\pi_{1}+\pi_{4}\right) / 2+\left(\epsilon_{\mathrm{S} 1}+\epsilon_{\mathrm{S} 2}\right) / 2, \\
& \mathrm{Z}_{\mathrm{S} 2}=\left(\mathrm{y}_{\mathrm{S} 12}+\mathrm{y}_{\mathrm{S} 13}\right) / 2=\mu+\mathrm{S}+\mathrm{T}_{\mathrm{SB}}+\tau_{\mathrm{B}}+\left(\pi_{2}+\pi_{3}\right) / 2+\left(\eta_{\mathrm{S} 1}+\eta_{\mathrm{S} 2}\right) / 2,
\end{aligned}
$$


for $S=1, \ldots, N_{1}$.

$$
\begin{aligned}
& \mathrm{Z}_{\mathrm{S} 3}=\left(\mathrm{y}_{\mathrm{S} 11}-\mathrm{y}_{\mathrm{S} 14}\right) / 2=\left(\pi_{1}-\pi_{4}\right) / 2+\left(\epsilon_{\mathrm{S} 1}-\epsilon_{\mathrm{S} 2}\right) / 2, \\
& \mathrm{Z}_{\mathrm{S} 3}=\left(\mathrm{y}_{\mathrm{S} 12}-\mathrm{y}_{\mathrm{S} 13}\right) / 2=\left(\pi_{2}-\pi_{3}\right) / 2+\left(\eta_{\mathrm{S} 1}-\eta_{\mathrm{S} 2}\right) / 2,
\end{aligned}
$$

Similarly, for sequence BAAB, let

$$
\begin{aligned}
& \mathrm{W}_{\mathrm{S} 1}=\left(\mathrm{y}_{\mathrm{S} 22}+\mathrm{y}_{\mathrm{S} 23}\right) / 2=\mu+\mathrm{S}+\mathrm{T}_{\mathrm{SA}}+\tau_{\mathrm{A}}+\left(\pi_{2}+\pi_{3}\right) / 2+\left(\epsilon_{\mathrm{S} 1}+\epsilon_{\mathrm{S} 1}\right) / 2, \\
& \mathrm{~W}_{\mathrm{S} 2}=\left(\mathrm{y}_{\mathrm{S} 21}+\mathrm{y}_{\mathrm{S} 24}\right) / 2=\mu+\mathrm{S}+\mathrm{T}_{\mathrm{SB}}+\tau_{\mathrm{B}}+\left(\pi_{1}+\pi_{4}\right) / 2+\left(\eta_{\mathrm{S} 1}+\eta_{\mathrm{S} 1}\right) / 2, \\
& \mathrm{~W}_{\mathrm{S} 3}=\left(\mathrm{y}_{\mathrm{S} 22}-\mathrm{y}_{\mathrm{S} 23}\right) / 2=\left(\pi_{2}-\pi_{3}\right) / 2+\left(\epsilon_{\mathrm{S} 1}-\epsilon_{\mathrm{S} 1}\right) / 2, \\
& \mathrm{~W}_{\mathrm{S} 4}=\left(\mathrm{y}_{\mathrm{S} 21}-\mathrm{y}_{\mathrm{S} 24}\right) / 2=\left(\pi_{1}-\pi_{4}\right) / 2+\left(\eta_{\mathrm{S} 1}-\eta_{\mathrm{S} 1}\right) / 2 .
\end{aligned}
$$

for $\mathrm{S}=\mathrm{N}_{1}+1, \ldots, \mathrm{N}_{1}+\mathrm{N}_{2}$.

Let $\mathbf{Z}_{\mathrm{S}}=\left(\mathrm{Z}_{\mathrm{S} 1}, \mathrm{Z}_{\mathrm{S} 2}, \mathrm{Z}_{\mathrm{S} 3}, \mathrm{Z}_{\mathrm{S} 4}\right)^{\prime}$, then the random vectors $\mathbf{Z}_{\mathrm{S}}, \mathrm{S}=1, \ldots, \mathrm{N}$ have

$$
E\left(\boldsymbol{Z}_{S}\right)=\left(\begin{array}{c}
\tau_{A}+\left(\pi_{1}+\pi_{4}\right) / 2 \\
\tau_{B}+\left(\pi_{2}+\pi_{3}\right) / 2 \\
\left(\pi_{1}-\pi_{4}\right) / 2 \\
\left(\pi_{2}-\pi_{3}\right) / 2
\end{array}\right)
$$

and covariance matrix

$$
\operatorname{Cov}\left(\boldsymbol{Z}_{S}\right)=\left(\begin{array}{cccc}
\sigma_{S}^{2}+\sigma_{A}^{2}+\sigma_{\epsilon}^{2} / 2 & \sigma_{S}^{2} & 0 & 0 \\
\sigma_{S}^{2} & \sigma_{S}^{2}+\sigma_{B}^{2}+\sigma_{\eta}^{2} / 2 & 0 & 0 \\
0 & 0 & \sigma_{\epsilon}^{2} / 2 & 0 \\
0 & 0 & 0 & \sigma_{\eta}^{2} / 2
\end{array}\right) .
$$

Similarly, let $\mathbf{W}_{\mathbf{S}}=\left(\mathrm{W}_{\mathrm{S} 1}, \mathrm{~W}_{\mathrm{S} 2}, \mathrm{~W}_{\mathrm{S} 3}, \mathrm{~W}_{\mathrm{S} 4}\right)^{\prime}$, then the random vectors $\mathbf{W}_{\mathrm{S}}, \mathrm{S}=\mathrm{N}_{1}+1, \ldots, \mathrm{N}_{1}+\mathrm{N}_{2}$ have different means but the same covariance matrix as $\mathbf{Z}_{\mathrm{S}}, \mathrm{S}=1, \ldots, \mathrm{N}$.

Let

$$
\boldsymbol{A}=\sum_{\text {seq }=1}\left(\boldsymbol{Z}_{\boldsymbol{S}}-\overline{\boldsymbol{Z}}\right)\left(\boldsymbol{Z}_{\boldsymbol{S}}-\overline{\boldsymbol{Z}}\right)^{\prime}, \quad \boldsymbol{B}=\sum_{s e q=2}\left(\boldsymbol{W}_{S}-\overline{\boldsymbol{W}}\right)\left(\boldsymbol{W}_{\boldsymbol{S}}-\overline{\boldsymbol{W}}\right)^{\prime},
$$


where

$$
\overline{\boldsymbol{Z}}=\frac{1}{N_{1}} \sum_{\text {seq }=1} \boldsymbol{Z}_{S}, \quad \overline{\boldsymbol{W}}=\frac{1}{N_{2}} \sum_{\text {seq }=2} \boldsymbol{W}_{\boldsymbol{S}} .
$$

By Corollary 7.2.1 of Anderson (1958), $\mathrm{A}$ is a Wishart Matrix with $\mathrm{df}=\mathrm{N}_{1}-1$ and $\mathrm{B}$ is also a Wishart Matrix with $\mathrm{df}=\mathrm{N}_{2}-1$.

Let $\mathbf{C}=\mathbf{A}+\mathbf{B}=\left(\mathrm{C}_{\mathrm{ij}}\right)_{4 \times 4}$ and denote $\sum=\left(\sigma_{\mathrm{ij}}\right)_{4 \times 4}=\operatorname{Cov}\left(\mathbf{Z}_{\mathrm{S}}\right)$. Then by Theorem 7.3. of Anderson (1958), $\mathbf{C}$ is a Wishart Matrix with degree of freedom $n=N-2$ and covariance matrix $\sum$. That is, $\mathrm{C} \sim \mathrm{W}\left(\sum, \mathrm{n}\right)$.

Let $\mathrm{D}=\mathrm{C}_{11}-\mathrm{C}_{22}-\mathrm{C}_{33}+\mathrm{C}_{44}$, then

$\mathrm{E}(\mathrm{D})=\mathrm{n}\left[\left(\sigma_{\mathrm{S}}{ }^{2}+\sigma_{\mathrm{A}}{ }^{2}+\sigma_{\epsilon}{ }^{2} / 2\right)-\left(\sigma_{\mathrm{S}}{ }^{2}+{\sigma_{\mathrm{B}}}^{2}+\sigma_{\eta}{ }^{2} / 2\right)-\sigma_{\epsilon}{ }^{2} / 2+\sigma_{\eta}{ }^{2} / 2\right]=\mathrm{n}\left(\sigma_{\mathrm{A}}{ }^{2}-\sigma_{\mathrm{B}}{ }^{2}\right)$, and

$$
\begin{aligned}
\operatorname{Var}(\mathrm{D})= & \operatorname{Var}\left(\mathrm{C}_{11}\right)+\operatorname{Var}\left(\mathrm{C}_{22}\right)+\operatorname{Var}\left(\mathrm{C}_{33}\right)+\operatorname{Var}\left(\mathrm{C}_{44}\right)-2 \operatorname{Cov}\left(\mathrm{C}_{11}, \mathrm{C}_{22}\right)-2 \operatorname{Cov}\left(\mathrm{C}_{11}, \mathrm{C}_{33}\right) \\
& +2 \operatorname{Cov}\left(\mathrm{C}_{11}, \mathrm{C}_{44}\right)+2 \operatorname{Cov}\left(\mathrm{C}_{22}, \mathrm{C}_{33}\right)-2 \operatorname{Cov}\left(\mathrm{C}_{22}, \mathrm{C}_{44}\right)-2 \operatorname{Cov}\left(\mathrm{C}_{33}, \mathrm{C}_{44}\right) \\
= & 2 \mathrm{n}\left({\sigma_{11}}^{2}+\sigma_{22}{ }^{2}+\sigma_{33}{ }^{2}+{\sigma_{44}}^{2}-2 \sigma_{12}{ }^{2}\right) .
\end{aligned}
$$

Since $\operatorname{Var}\left(\mathrm{C}_{\mathrm{ij}}\right)=2 n \sigma_{\mathrm{ii}}{ }^{2}$ and $\operatorname{Cov}\left(\mathrm{C}_{\mathrm{ii}}, \mathrm{C}_{\mathrm{jj}}\right)=\mathrm{n}\left(\sigma_{\mathrm{ij}} \sigma_{\mathrm{ij}}+\sigma_{\mathrm{ij}} \sigma_{\mathrm{ij}}\right)=2 n \sigma_{\mathrm{ij}}{ }^{2}$ by page 161 of Anderson (1958), and the estimates of $\sigma_{\mathrm{ij}}$ are

$$
\hat{\sigma}_{i j}=\frac{C_{i j}}{n}
$$

We have

$$
\begin{gathered}
\hat{E}(D)=C_{11}-C_{22}-C_{33}+C_{44}, \\
\operatorname{Var}(D)=2 n\left[\left(C_{11} / n\right)^{2}+\left(C_{22} / n\right)^{2}+\left(C_{33} / n\right)^{2}+\left(C_{44} / n\right)^{2}-2\left(C_{12} / n\right)^{2}\right] .
\end{gathered}
$$

If $\sigma_{\mathrm{A}}{ }^{2}={\sigma_{\mathrm{B}}}^{2}$, then the between-subject variance components $\sigma_{\mathrm{A}}{ }^{2}+{\sigma_{\mathrm{S}}}^{2}$ and ${\sigma_{\mathrm{B}}}^{2}+{\sigma_{\mathrm{S}}}^{2}$ are respectively equal as well. 
Let

$$
Z=\frac{\hat{E}(D)}{\operatorname{Var}(D)}=\frac{C_{11}-C_{22}-C_{33}+C_{44}}{\sqrt{2 / n} \cdot \sqrt{C_{11}^{2}+C_{22}^{2}+C_{33}^{2}+C_{44}^{2}-2 C_{12}^{2}}}
$$

$\mathrm{D}$ is a linear combination of dependent $\chi^{2}$ variable. Thus, an approximate $\mathrm{z}$-statistic will be used to derive $\mathrm{p}$-values for the test of $\mathrm{H}_{0}: \sigma_{\mathrm{A}}{ }^{2}=\sigma_{\mathrm{B}}{ }^{2}$. Hence, the p-value for testing the between-subject variability is

$$
\mathrm{p}=2(1-\Psi(Z))
$$

where $\Psi$ is the standard normal distribution function.

The $\mathrm{p}$-value for testing the within-subject variability $\left(\mathrm{H}_{0}: \sigma_{\epsilon}{ }^{2}=\sigma_{\eta}{ }^{2}\right)$ is from a F-test. Let

$$
F=\frac{\hat{\sigma}_{\epsilon}^{2}}{\hat{\sigma}_{\eta}^{2}}=\frac{C_{33}^{2}}{C_{44}^{2}}
$$

then $\mathrm{F} \sim \mathrm{F}(\mathrm{n}, \mathrm{n})$. Hence the within-subject $\mathrm{p}$-value is

$$
\mathrm{p}=\mathrm{F}_{(\mathrm{n}, \mathrm{n})}(\mathrm{r})
$$

where $r=\max (F, 1 / F)$.

Since $\sigma_{\mathrm{S}}{ }^{2}+\sigma_{\mathrm{A}}{ }^{2}=\left({\sigma_{\mathrm{S}}}^{2}+\sigma_{\mathrm{A}}{ }^{2}+\sigma_{\epsilon}{ }^{2} / 2\right)-\sigma_{\epsilon}{ }^{2} / 2=\sigma_{11}-\sigma_{33}$ is the between-subject variance component for Treatment $\mathrm{A}, \sigma_{\mathrm{S}}{ }^{2}+\sigma_{\mathrm{A}}{ }^{2}$ may be estimated by $\left(\mathrm{C}_{11}-\mathrm{C}_{33}\right) / \mathrm{n}$. Similarly, the between-subject variance component for Treatment $B$ may be estimated by $\left(C_{22}-C_{44}\right) / n$.

The within-subject variance for Treatment $\mathrm{A}$ is estimated by $2 \mathrm{C}_{33} / \mathrm{n}$, and the within-subject variance for Treatment $B$ is estimated by $2 \mathrm{C}_{44} / \mathrm{n}$.

If it is desired to estimate the coefficient of variation of the variance components, the problem may be simplified by taking the natural log of each value and compute variance components of transformed values. The square root of variance components when multiplied by 100 yield an estimate of the corresponding coefficients of variation of the untransformed values. That is

$$
100 \sqrt{\operatorname{Var}(\ln X)} \approx 100 \frac{S D_{x}}{\mu_{x}} .
$$




\section{Evaluation of Individual Bioequivalence}

It was further desired to determine whether the average effect of the treatments may be applied to the population as a whole or whether each subject had his own unique difference between the treatments. If $\sigma_{\mathrm{A}}{ }^{2}=\sigma_{\mathrm{B}}{ }^{2}=0$ and $\sigma_{\epsilon}{ }^{2}=\sigma_{\eta}{ }^{2}$ then the treatment effect difference $\tau_{\mathrm{A}}-\tau_{\mathrm{B}}$ was equally valid for each individual subject.

Define

$\mathrm{D}_{\mathrm{TC}}=\mathrm{Z}_{\mathrm{S} 1}-\mathrm{Z}_{\mathrm{S} 2}$ for sequence 1 , and

$\mathrm{D}_{\mathrm{TC}}=\mathrm{W}_{\mathrm{S} 1}-\mathrm{W}_{\mathrm{S} 2}$ for sequence 2 .

Then

$\mathrm{E}\left(\mathrm{D}_{\mathrm{TC}}\right)=\tau_{\mathrm{A}}-\tau_{\mathrm{B}}+\left(\pi_{1}-\pi_{2}-\pi_{3}+\pi_{4}\right) / 2$, for sequence 1 subjects, and

$\mathrm{E}\left(\mathrm{D}_{\mathrm{TC}}\right)=\tau_{\mathrm{A}}-\tau_{\mathrm{B}}-\left(\pi_{1}-\pi_{2}-\pi_{3}+\pi_{4}\right) / 2$, for sequence 2 subjects, and

$\operatorname{Var}\left(\mathrm{D}_{\mathrm{TC}}\right)=\sigma_{\mathrm{A}}^{2}+\sigma_{\mathrm{B}}^{2}+\sigma_{\epsilon}^{2} / 2+\sigma_{\eta}^{2} / 2$, for both sequences.

Remember that treatment A was a Capsule and B was a Tablet.

Furthermore, define

$\mathrm{D}_{\mathrm{CC}}=2 \mathrm{Z}_{\mathrm{S} 3}$ for sequence 1 , and

$\mathrm{D}_{\mathrm{CC}}=2 \mathrm{~W}_{\mathrm{S} 3}$ for sequence 2 .

Then

$\mathrm{E}\left(\mathrm{D}_{\mathrm{CC}}\right)=\pi_{1}-\pi_{4}$, for sequence 1 subjects, and

$\mathrm{E}\left(\mathrm{D}_{\mathrm{CC}}\right)=\pi_{2}-\pi_{3}$, for sequence 2 subjects, and

$\operatorname{Var}\left(D_{\mathrm{CC}}\right)=\sigma_{\epsilon}^{2}$, for both sequences.

If $\sigma_{\mathrm{A}}{ }^{2}=\sigma_{\mathrm{B}}{ }^{2}=0$ and $\sigma_{\epsilon}{ }^{2}=\sigma_{\eta}{ }^{2}$, then

$$
\sigma_{\mathrm{A}}^{2}+\sigma_{\mathrm{B}}^{2}+\sigma_{\epsilon}^{2} / 2+\sigma_{\eta}{ }^{2} / 2=\sigma_{\epsilon}^{2} .
$$

Furthermore, define

$$
r=\frac{\sigma_{A}^{2}+\sigma_{B}^{2}+\sigma_{\epsilon}^{2} / 2+\sigma_{\eta}^{2} / 2}{\sigma_{\epsilon}^{2}} .
$$

Then $r=1$ when $\sigma_{A}{ }^{2}=\sigma_{B}{ }^{2}=0$ and $\sigma_{\epsilon}{ }^{2}=\sigma_{\eta}{ }^{2}$. The parameter maybe used as an index of the extent to which average difference between the capsule and the tablet may be applied to individual subjects. Values of $r$ closed to 1 indicate good applicability of the population average difference to individual subjects. Large values of $r$ indicate that each patient has his own rule. 
Let

$$
S S_{b e t}=\sum_{s e q=1}\left(D_{T C}-\bar{D}_{T C}^{(1)}\right)^{2}+\sum_{s e q=2}\left(D_{T C}-\bar{D}_{T C}^{(2)}\right)^{2},
$$

where

$$
\bar{D}_{T C}^{(1)}=\frac{1}{N_{1}-1} \sum_{s e q=1} D_{T C}, \bar{D}_{T C}^{(2)}=\frac{1}{N_{2}-1} \sum_{s e q=2} D_{T C},
$$

and

$$
S S_{\text {within }}=\sum_{\text {seq }=1}\left(D_{C C}-\bar{D}_{C C}^{(1)}\right)^{2}+\sum_{s e q=2}\left(D_{C C}-\bar{D}_{C C}^{(2)}\right)^{2} .
$$

Then

$$
\mathrm{SS}_{\mathrm{bet}} /\left(\sigma_{\mathrm{A}}^{2}+\sigma_{\mathrm{B}}^{2}+\sigma_{\epsilon}^{2} / 2+\sigma_{\eta}^{2} / 2\right) \sim \chi^{2}(\mathrm{n}),
$$

and

$$
\mathrm{SS}_{\text {within }} /\left(2 \sigma_{\epsilon}^{2}\right) \sim \chi^{2}(\mathrm{n}) \text {. }
$$

Let

$$
R=\frac{2 S S_{\text {bet }}}{S S_{\text {within }}}=\frac{2\left(\sum_{\text {seq }=1}\left(D_{T C}-\bar{D}_{T C}^{(1)}\right)^{2}+\sum_{s e q=2}\left(D_{T C}-\bar{D}_{T C}(2)\right)^{2}\right)}{\sum_{s e q=1}\left(D_{C C}-\bar{D}_{C C}^{(1)}\right)^{2}+\sum_{s e q=2}\left(D_{C C}-\bar{D}_{C C}^{(2)}\right)^{2}} .
$$

Then,

$$
\mathrm{R} / \mathrm{r} \sim \mathrm{F}(\mathrm{n}, \mathrm{n}) .
$$

Since $\operatorname{Pr}\left(\mathrm{R} / \mathrm{r}>\mathrm{F}_{(\mathrm{n}, \mathrm{n})}(0.05)\right)=0.95$, the upper $95 \%$ confidence limit for $\mathrm{r}$ can be calculated by

$$
\mathrm{R} / \mathrm{F}_{(\mathrm{n}, \mathrm{n})}(0.05) \text {. }
$$




\section{Examples}

To illustrate our approach, 4 samples were randomly generated using the model described in Chapter 2. Each sample was generated using a different set of parameters. There are 24 subjects in a group, 12 in each sequence. The data was log transformed before analysis. Tables 1 and 2 give the variance component estimates and p-values from different set of parameters. Table 3 gives the test results for individual bioequivalence. The STD of the transformed data is essentially the $\mathrm{CV}$ of the original data. For a subject, the interclass correlation is calculated as

$$
\frac{\sigma_{S}^{2}}{\sqrt{\sigma_{S}^{2}+\sigma_{A}^{2}+\sigma_{\epsilon^{\prime}}^{2}} \cdot \sqrt{\sigma_{S}^{2}+\sigma_{B}^{2}+\sigma_{\eta}^{2}}} .
$$

In the first sample, the parameters are set as follows:

$\sigma_{\mathrm{S}}=0.30, \sigma_{\mathrm{A}}=0, \sigma_{\mathrm{B}}=0.40, \sigma_{\epsilon}=0.05$, and $\sigma_{\eta}=0.10$. Therefore the interclass correlation = 0.58 .

The within-subject $\% \mathrm{CV}$ for tablet $=100 \times \sigma_{\eta}=10$. The within-subject $\% \mathrm{CV}$ for capsule $=$ $100 \times \sigma_{\epsilon}=5$. The estimates for the $\% \mathrm{CV}$ are 11.25 and 5.46 respectively. It turn out that the pvalue for testing the equality of the two $\% \mathrm{CV}$ is 0.001 (Table 1 ). In this sample, the betweensubject $\% \mathrm{CV}$ for tablet $=100 \times\left(\sigma_{\mathrm{S}}{ }^{2}+{\sigma_{\mathrm{B}}}^{2}\right)^{1 / 2}=50$, and the between-subject $\% \mathrm{CV}$ for capsule $=$ $100 \times\left(\sigma_{\mathrm{S}}{ }^{2}+\sigma_{\mathrm{A}}{ }^{2}\right)^{1 / 2}=30$, The estimates for the $\% \mathrm{CV}$ are 47.31 and 29.55 respectively. P-value for testing the equality of the two \% CV is 0.035 (Table 2).

Also from this sample, the individual bioequivalence index $r=66.50$. Its estimate is 49.16 and the $p$-value for testing $r=1$ is $<0.001$ (Table 3 ).

As seen from Tables 1, 2 and 3, for all these four samples the test essentially give the correct conclusion. 
Table 1. Within-subject variability of pharmacokinetic parameters by formulation

\begin{tabular}{|c|l|l|l|l|c|}
\hline Sample & Information & $\begin{array}{c}\text { Interclass } \\
\text { Correlation }\end{array}$ & $\begin{array}{c}\text { Tablet } \\
\text { Within \%CV }\end{array}$ & $\begin{array}{c}\text { Capsule } \\
\text { Within \%CV }\end{array}$ & $\begin{array}{c}\text { P-Value } \\
\text { Within }\end{array}$ \\
\hline \multirow{2}{*}{1} & Parameters & 0.580 & 10 & 5 & \\
\cline { 2 - 6 } & Estimates & & 11.25 & 5.46 & 0.001 \\
\hline \multirow{2}{*}{2} & Parameters & 0.364 & 30 & 30 & 0.889 \\
\cline { 2 - 6 } & Estimates & & 33.75 & 32.76 & \\
\hline \multirow{2}{*}{3} & Parameters & 0.900 & 10 & 10 & 0.889 \\
\cline { 2 - 6 } & Estimates & & 11.25 & 10.92 & 0.889 \\
\hline \multirow{2}{*}{4} & Parameters & 0.500 & 10 & 10 & 10.92 \\
\cline { 2 - 6 } & Estimates & & 11.25 & & \\
\hline
\end{tabular}

Table 2. Between-subject variability of pharmacokinetic parameters by formulation

\begin{tabular}{|c|l|l|l|l|c|}
\hline \multirow{2}{*}{ Sample } & Information & $\begin{array}{c}\text { Interclass } \\
\text { Correlation }\end{array}$ & $\begin{array}{c}\text { Tablet } \\
\text { Between \%CV }\end{array}$ & $\begin{array}{c}\text { Capsule } \\
\text { Between \%CV }\end{array}$ & $\begin{array}{c}\text { P-Value } \\
\text { Between }\end{array}$ \\
\hline \multirow{2}{*}{1} & Parameters & 0.580 & 50 & 30 & \\
\cline { 2 - 6 } & Estimates & & 47.31 & 29.55 & 0.035 \\
\hline \multirow{2}{*}{2} & Parameters & 0.364 & 50 & 30 & 0.077 \\
\cline { 2 - 6 } & Estimates & & 46.34 & 25.63 & \\
\hline \multirow{2}{*}{3} & Parameters & 0.900 & 30 & 30 & 0.986 \\
\cline { 2 - 6 } & Estimates & & 29.39 & 29.43 & \\
\hline \multirow{2}{*}{4} & Parameters & 0.500 & 30 & 30 & 0.940 \\
\cline { 2 - 6 } & Estimates & & 28.50 & 28.06 & \\
\hline
\end{tabular}

Table 3. Analysis of individual bioequivalence between formulation

\begin{tabular}{|c|c|c|c|c|c|}
\hline Sample & $\begin{array}{c}\text { Interclass } \\
\text { Correlation }\end{array}$ & $\begin{array}{c}\text { Population } \\
\text { Individual } \\
\text { Bioequivalence } \\
\text { Index }\end{array}$ & $\begin{array}{c}\text { Sample } \\
\text { Individual } \\
\text { Bioequivalence } \\
\text { Index }\end{array}$ & $\begin{array}{c}95 \% \text { Upper } \\
\text { Confidence } \\
\text { Band for } \\
\text { Index }\end{array}$ & $\begin{array}{c}\text { P-Value for } \\
\text { Testing } \\
\text { Different } \\
\text { from 1 }\end{array}$ \\
\hline 1 & 0.580 & 66.50 & 49.16 & 100.7 & $<0.001$ \\
\hline 2 & 0.364 & 2.78 & 1.98 & 4.06 & 0.058 \\
\hline 3 & 0.900 & 1.00 & 0.73 & 1.49 & 0.769 \\
\hline 4 & 0.500 & 9.00 & 8.13 & 16.65 & $<0.001$ \\
\hline
\end{tabular}




\section{Summary}

In order to compare within- and between-subject variance components in a cross-over design, it is necessary to define a new mixed linear model for a pharmacokinetic crossover trial. Terms have to be added to the model for the subject by treatment interaction for each dosage form investigated. Error terms in the model also have to differ between dosage forms.

Comparisons of means and within-subject variance components may be done in a straight forward manner. A test of the difference between the between-subject components is developed using a Z-test and an estimate of the covariance of the between-subject variance components.

The size of the variance of the within-subject, between treatment difference relative to the variance of the within-subject, within standard dosage form difference provides an index of the extent of the appropriateness of using the population average relative bioavailability as a measure of each individual subject's relative bioavailability. This index provides a measure of the relative size of the subject by treatment interactions. It also has a scaled F-distribution which is very easy to work with in applications.

Examples presented show that in cases where the size of within- and between-subject CV may be of concern, differences can be found with moderate size samples. Examples presented also show that it may be possible to have equal between and within-subject CV's for 2 dosage forms, but at the same time the use of the average bioavailability is inappropriate because the subject by dosage form interactions are relatively large compared to the within-subject CV.

\section{Reference}

1. Anderson, T. W. (1958). An Introduction of Multivariate Statistical Analysis. John Wiley \& Son, Inc., New York., 